\title{
Altruism or Self-Interest? Author Motivations to Publish Open Access
}

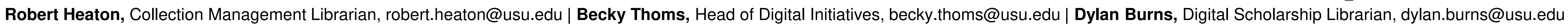

\section{ABSTRACT}

In 2016, according to Scopus data, 249 Utah State University (USU) authors published Open Access (OA). This was in comparison to the 28 authors who applied to use the Library's OA fund during that same period. The literature speaks little as to what motivates authors to publish OA, and we saw an opportunity to contribute to the OA conversation by asking USU authors about their motivations. We used Scopus to analyze the trends by college and tenure status and surveyed all these authors in summer 2017 to gather qualitative data (response rate was $34.5 \%$ ).

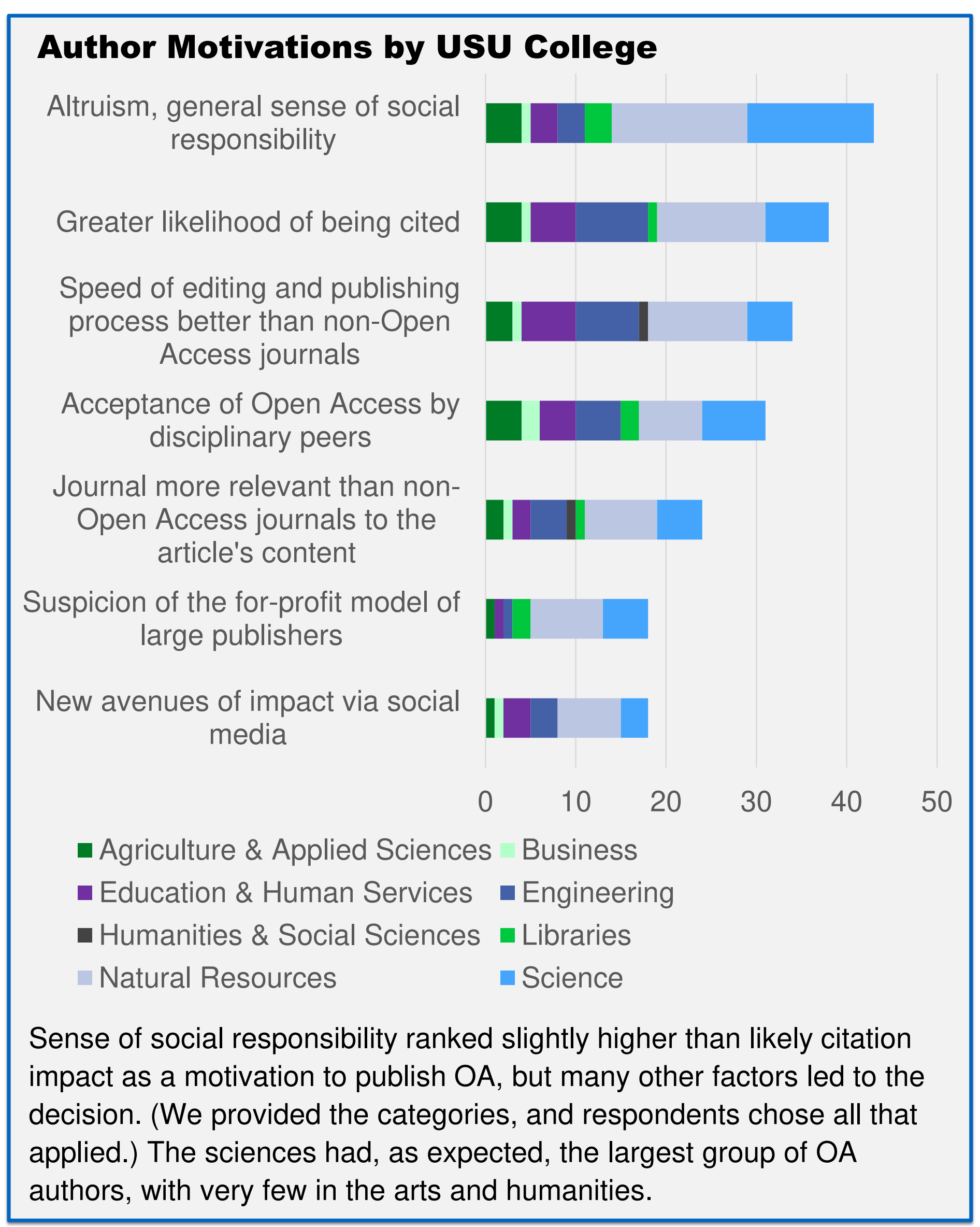

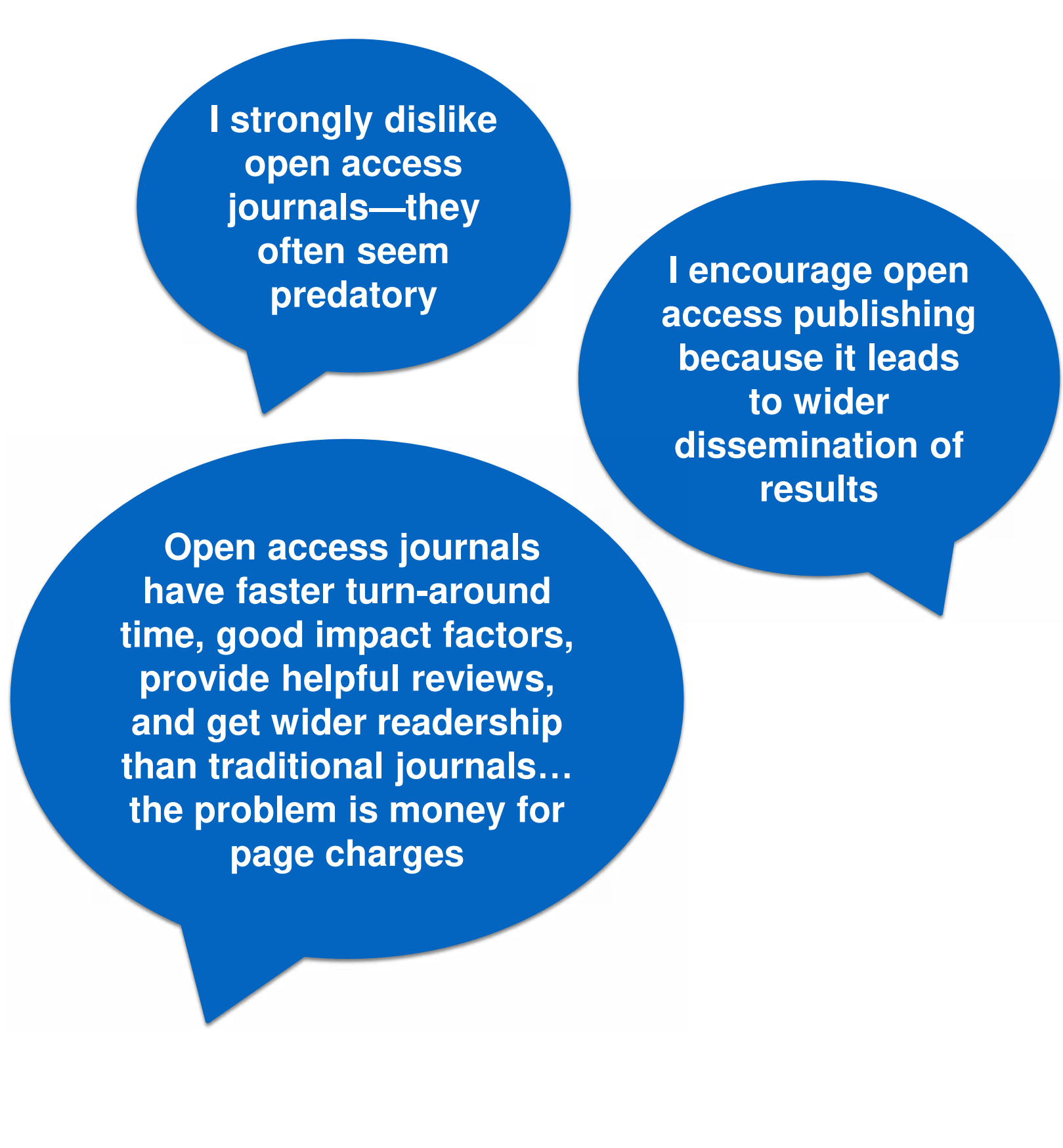

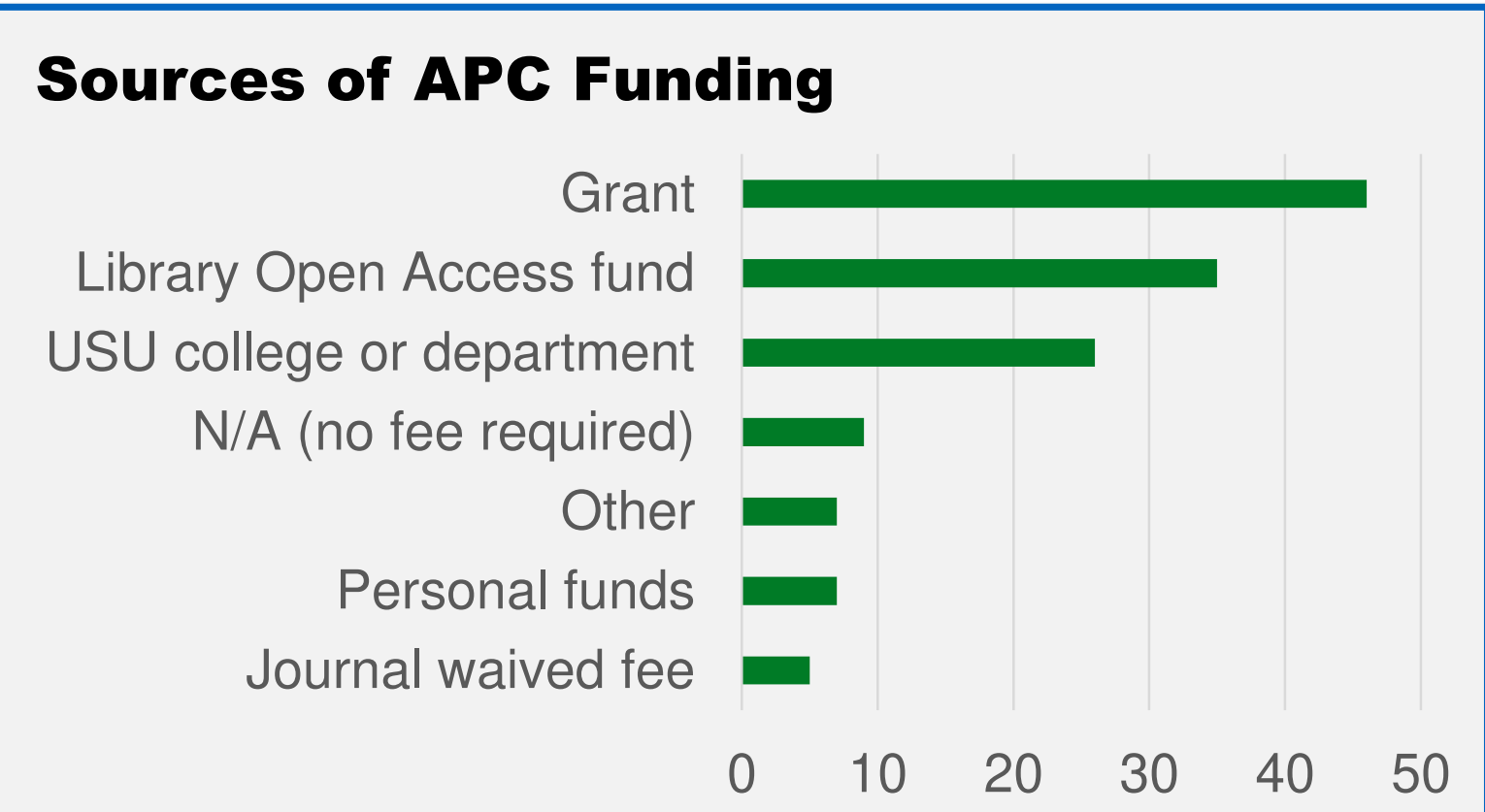

Authors are motivated by the availability of funding for article processing charges (APCs). Authors confirmed that external grants were the primary source of APC funding, with the Library's OA fund surprisingly close behind, followed by funding from the author's college or department.

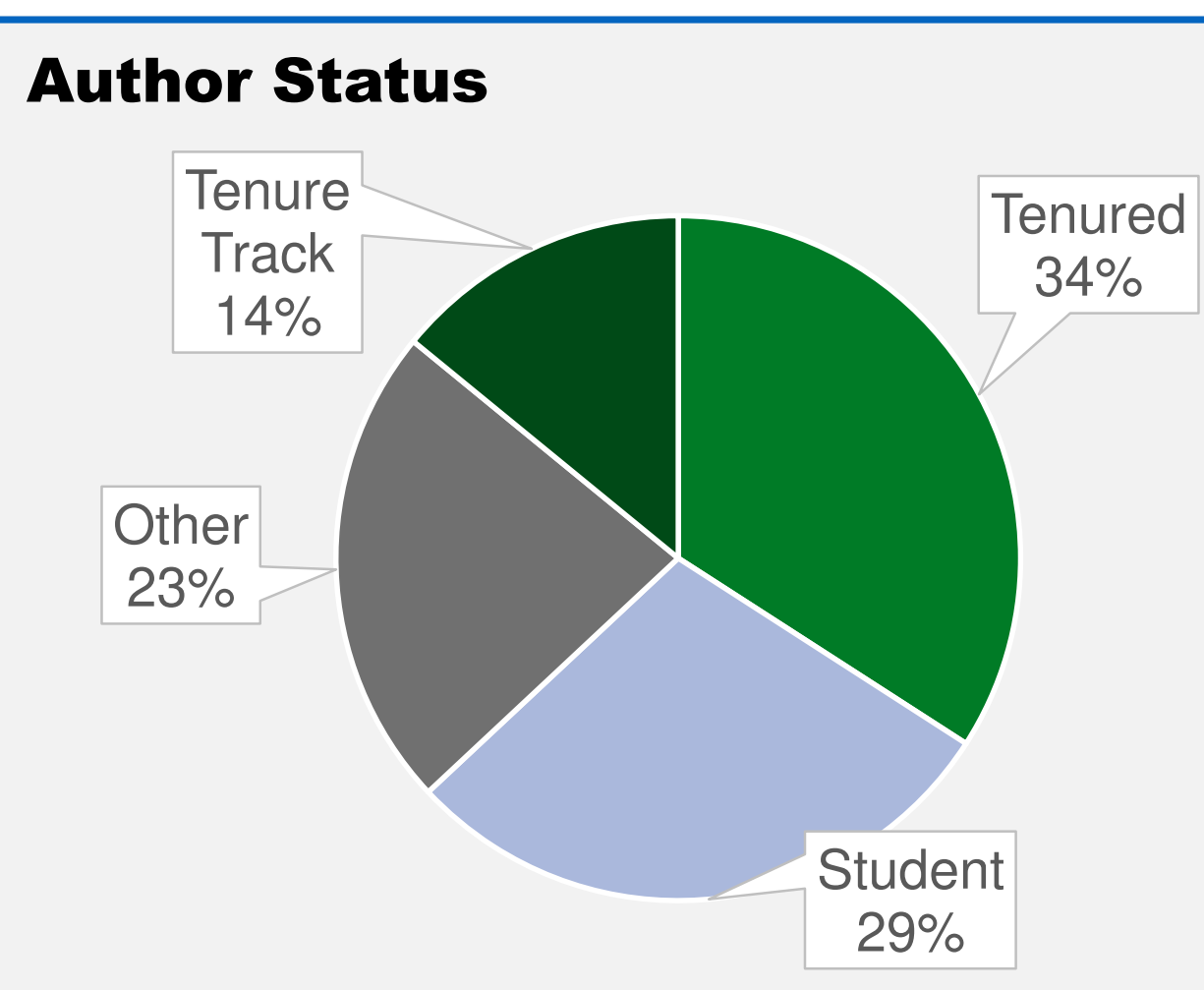

Likelihood to publish Open Access does not seem to differ on the basis of tenure status. Tenure-track faculty are much fewer in number than tenured at USU, so their OA contributions are proportionally appropriate. Students (mostly graduate students) comprised an unexpectedly large group.

\section{FUTURE PLANS}

Our findings suggest several focus areas for the

Library's analysis and outreach:

- Track trends in key statistics

- Find out whether authors would have published OA if they had not received funding

- Plan outreach to underrepresented colleges

- Seek centralized APC funding from University administration

- Campaign for OA acceptance in tenure process

- Consider marketing Library OA fund to past OA authors

\section{UtahStateUniversity} UNIVERSITY LIBRARIES 